\title{
The Challenges of Delta Variant of Coronavirus and Indian Vaccinations Can Envision the Coronavirus and Its Effects
}

\author{
Jitendra Malviya ${ }^{1, ~ *}$, Arvind Parmar², Lokesh Parmar², Roshni Khan², Rituja Roy², \\ Sushmita Kanade ${ }^{2}$, Prince Giri ${ }^{2}$, Balram Rathore ${ }^{2}$ \\ ${ }^{1}$ Department of Life Sciences and Biological Sciences, IES University, Bhopal, India \\ ${ }^{2}$ Department of Pharmacy, Barkatullah University, Bhopal, India
}

Email address:

jitmalviya123@gmail.com (J. Malviya)

${ }^{*}$ Corresponding author

\section{To cite this article:}

Jitendra Malviya, Arvind Parmar, Lokesh Parmar, Roshni Khan, Rituja Roy, Sushmita Kanade, Prince Giri, Balram Rathore. The Challenges of Delta Variant of Coronavirus and Indian Vaccinations Can Envision the Coronavirus and Its Effects. American Journal of Biomedical and Life Sciences. Vol. 9, No. 4, 2021, pp. 219-229. doi: 10.11648/j.ajbls.20210904.16

Received: June 6, 2021; Accepted: August 7, 2021; Published: August 31, 2021

\begin{abstract}
Since the outbreak of the novel corona virus disease COVID-19, precipitated by way of the SARS-CoV-2 virus, this sickness has unfolded hastily round the globe. Considering the practicable risk of a pandemic, scientists and medical doctors have been racing to apprehend this new virus and the pathophysiology of this disorder to discover feasible therapy regimens and find out fantastic therapeutic sellers and vaccines. To guide the cutting-edge lookup and development, CAS has produced a extraordinary record to furnish an overview of posted scientific statistics with an emphasis on patents in the CAS content material collection. It highlights antiviral techniques involving small molecules and biologics concentrated on complicated molecular interactions concerned in corona virus contamination and replication. The drug-repurposing effort documented herein focuses principally on dealers recognized to be superb in opposition to different RNA viruses such as SARS-CoV and MERS-CoV. The current secondary data have been chosen for the study while text 16 research articles to focus the study. The review is focus on that the challenges of coronaviruses and the new strains in Indian population due to constantly virus has changed through mutation appeared and disappeared too the more diverse and spread easily and resistant to treatments or vaccines. The vaccination in India is slow rate due to unavailability of the raw materials; the two Indian vaccine development companies have not able to provided vaccines as per the requirement. Unawareness has also been a biggest problem to the pandemic situation in the second wave of the coronavirus with new variants. The present study is deals with the challenges of new variants of coronavirus; the conditions of health system; Crisis of medicine, oxygen cylinder, failure of management increase more cases and finally the vaccination process; management and availability.
\end{abstract}

Keywords: SARSCOV-2 Antigen, Spike Protein, Covaxin, Covishield Vaccine

\section{Introduction}

The viability of immunizations in managing variations is anything but another worry. Scientists have worried about everything from the two variants of COVID-19 B.1.1.7 in the U.K. also, B.1.351 in South Africa to P.1 in Brazil and B.1.429 and B.1.232 in California [1]. This specific Coronavirus variation is in any event incompletely behind the mind-boggling second wave in India, the current worldwide focal point of the pandemic. The World Wellbeing Association has now raised B.1.617 from a "variation of interest" to a "variation of concern." Specialists like General
Wellbeing Britain are now regarding it as the last mentioned, which means there's a painful thing over at least one of the standards on which an infection is arbitrated including how quick it communicates, the number of it executes, and whether it excuses documentation or varieties vaccinations less compelling. Of the numerous progressions in the microbe, the two of most prominent concern effect a bit of the spike protein, called the receptor restricting area that is critical to the infection getting into human cells. Another investigation has tracked down that a passage driven by the B.1.617 spike 
protein (G142D, E154K, L452R, E484Q, D614G, P681R, and $\mathrm{Q} 1071 \mathrm{H})$ concerning the Wuhun-Hu1 sequence was "mostly safe against balance by antibodies evoked upon disease or inoculation with the Comirnaty/BNT162b2 immunization."[2]. Novel technology the Pfizer-BioNTech m-RNA vaccine employs a novel technology in the form of small piece of genetic material from the coronavirus called a messenger ribonucleic acid to make a vaccine for the coronavirus. Interim Phase-3 efficacy trials in Americans showed that those inoculated were $95 \%$ more likely to be protected than those who didn't take the vaccine. [3].

Table 1. COVID-19 INDIA.

\begin{tabular}{|c|c|c|c|}
\hline \multirow{2}{*}{ S. No. } & \multirow{2}{*}{ Name of State / UT } & \multicolumn{2}{|c|}{ Active Cases* } \\
\hline & & Total & Change since yesterday \\
\hline 1 & Andaman and Nicobar Islands & 232 & 18 \\
\hline 2 & Andhra Pradesh & 203787 & 2745 \\
\hline 3 & Arunachal Pradesh & 2202 & 35 \\
\hline 4 & Assam & 43325 & 166 \\
\hline 5 & Bihar & 89564 & 6714 \\
\hline 6 & Chandigarh & 8158 & 283 \\
\hline 7 & Chhattisgarh & 115964 & 3486 \\
\hline 8 & Dadra \& Nagar Haveli Daman \& Diu & 927 & 129 \\
\hline 9 & Delhi & 71794 & 5923 \\
\hline 10 & Goa & 32387 & 566 \\
\hline 11 & Gujarat & 117373 & 5474 \\
\hline 12 & Haryana & 99007 & 4133 \\
\hline 13 & Himachal Pradesh & 39623 & 385 \\
\hline 14 & Jammu and Kashmir & 52001 & 847 \\
\hline 15 & Jharkhand & 45056 & 3412 \\
\hline 16 & Karnataka & 598625 & 5527 \\
\hline 17 & Kerala & 442550 & 3282 \\
\hline 18 & Ladakh & 1554 & 7 \\
\hline 19 & Lakshadweep & 1163 & 71 \\
\hline 20 & Madhya Pradesh & 104444 & 3672 \\
\hline 21 & Maharashtra & 521683 & 14021 \\
\hline 22 & Manipur & 5898 & 329 \\
\hline 23 & Meghalaya & 4014 & 288 \\
\hline 24 & Mizoram & 2065 & 85 \\
\hline 25 & Nagaland & 3741 & 190 \\
\hline 26 & Odisha & 94740 & 3039 \\
\hline 27 & Puducherry & 17424 & 856 \\
\hline 28 & Punjab & 79359 & 591 \\
\hline 29 & Rajasthan & 212753 & 864 \\
\hline 30 & Sikkim & 3002 & 56 \\
\hline 31 & Tamil Nadu & 195339 & 11567 \\
\hline 32 & Telangana & 54832 & 2085 \\
\hline 33 & Tripura & 4230 & 196 \\
\hline 34 & Uttarakhand & 79379 & 1075 \\
\hline 35 & Uttar Pradesh & 193815 & 10843 \\
\hline 36 & West Bengal & 131792 & 1579 \\
\hline Total\# & & 3673802 & 31091 \\
\hline
\end{tabular}

Table 1. Continued.

\begin{tabular}{lllll}
\hline \multirow{2}{*}{ S. No. } & \multicolumn{2}{l}{ Cured/Discharged/Migrated } & Deaths** & Change since yesterday \\
\cline { 2 - 5 } & Cumulative & Change since yesterday & Cumulative & 2 \\
\hline 1 & 6225 & 12 & 85 & 96 \\
2 & 1175843 & 19177 & 9173 & 5 \\
3 & 19094 & 223 & 77 & 76 \\
4 & 274247 & 4168 & 2060 & 77 \\
5 & 544445 & 14131 & 3670 & 8 \\
6 & 45268 & 925 & 617 & 172 \\
7 & 772500 & 10908 & 11461 & 289 \\
8 & 8404 & 207 & 4 & 61 \\
9 & 1288280 & 14140 & 20907 & 104 \\
10 & 98200 & 2960 & 1998 & 8944 \\
11 & 609031 & 15365 & & \\
\hline
\end{tabular}




\begin{tabular}{lllll}
\hline \multirow{2}{*}{ S. No. } & \multicolumn{2}{l}{ Cured/Discharged/Migrated* } & Deaths** & Change since yesterday \\
\cline { 2 - 5 } & Cumulative & 14577 & Cumulative & 164 \\
\hline 12 & 570227 & 3362 & 6402 & 67 \\
13 & 111896 & 3814 & 2198 & 60 \\
14 & 181762 & 7112 & 3027 & 76 \\
15 & 260602 & 35879 & 4366 & 373 \\
16 & 1510557 & 31319 & 21085 & 93 \\
17 & 1636790 & 231 & 6243 & 2 \\
18 & 14439 & 102 & 163 & 88 \\
19 & 3392 & 11671 & 13 & 695 \\
20 & 605423 & 53249 & 6841 & 16 \\
21 & 4707980 & 381 & 79552 & 12 \\
22 & 31872 & 327 & 552 & 13 \\
23 & 17909 & 207 & 280 & 22 \\
24 & 6411 & 72 & 23 & 30 \\
25 & 13600 & 9329 & 190 & 180 \\
26 & 491674 & 1088 & 2273 & 155 \\
27 & 62424 & 8446 & 1099 & 6 \\
28 & 393148 & 13270 & 11477 & 288 \\
29 & 616589 & 170 & 6472 & 29 \\
30 & 7655 & 20037 & 198 & 3 \\
31 & 1318982 & 6361 & 17056 & 181 \\
32 & 462981 & 250 & 2896 & 311 \\
33 & 35396 & 4519 & 429 & 136 \\
34 & 193780 & 26179 & 4426 & 3890 \\
35 & 1385855 & 19131 & 16957 & 12993 \\
36 & 950017 & 353299 & 266207 & \\
Total\# & 20432898 & & & \\
\hline
\end{tabular}

\section{Source:}

https:/www.mohfw.gov.in/*(IncludingforeignNationals)/**(morethan70\%casesduetocomorbidities)/\#Stateswisedistributionissubjecttofurtherverificationandre conciliation/\#OurfiguresarebeingreconciledwithICMR.

\section{Criticize the India's Satisfaction over COVID-19}

A restricted scale examination of 123 trained professionals, specialists and other clinical staff at a specific diabetes treatment center in New Delhi found that of the 113 agents vaccinated (107 with the vital two bits), 18 got tainted with COVID, anyway only one individual should be hospitalized. The individual was thusly delivered, I acquired from one of the subject matter experts. It's not known whether this social affair was introduced to B.1.617. That is just something more we don't know amidst the predominant issue in India. People are scrambling to find a crisis center bed or an oxygen chamber. Or on the other hand if they're well a counter acting agent shot. Crematoriums are full, and terrified inhabitants are dumping bodies into the stream, also as during the 1918 Spanish Flu, a scene monetary savant ChinmayTumbe portrays in his book, The Time of Pandemics. Simply allowing the Coronavirus to run its course in a general population of 1.4 billion would be morally weak. It would similarly be unsafe: The more it takes to tame India's ensuing wave, the higher the threat of a variety that moves from neutralizer confirmation. One-sixth of mankind can't be neglected without a huge hit to an overall economy that is fretful to continue. Two people from the Indian unexpected, invited as guests, attempted positive, inciting self-partition for SubrahmanyamJaishankar, the new pastor. A PR disaster for the host, yet furthermore an update that it can't be old news for the world until the Indian situation goes leveled out. Singapore's greatest powerful gathering, at one of the city's tremendous crisis facilities, is being credited to B.1.617.2. This sub-lineage of the Indian variety is more overwhelming and "causing greater packs than already,". As countries help India including inoculation stocks to oxygen, they should therefore demand real itemizing of case and loss data - and significantly more conspicuous genomic examination of the emerging varieties than is at present being coordinated. In a country that puts wholeheartedly in being the world's medication capital, neighborhood labs are more than talented. In any case, they can't review the risk by sequencing fairly in excess of 11,000 models out of 22 million or more cases [4].

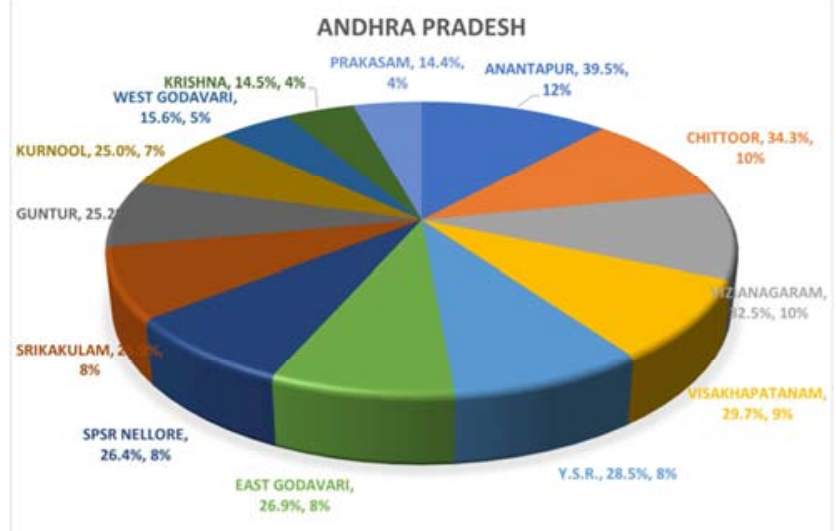

A 


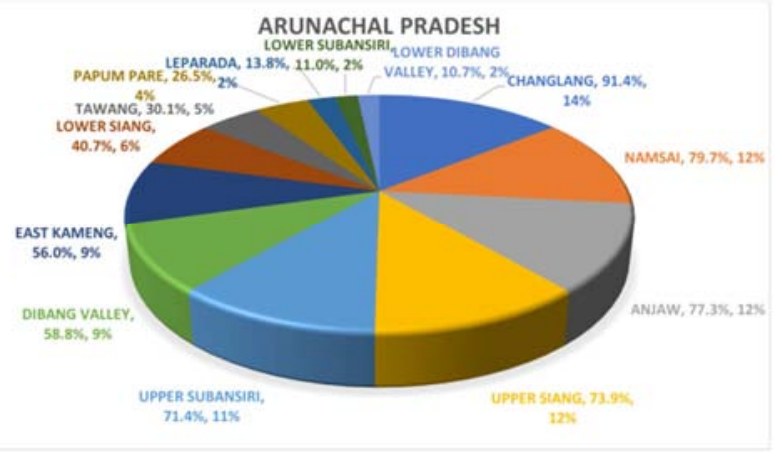

B

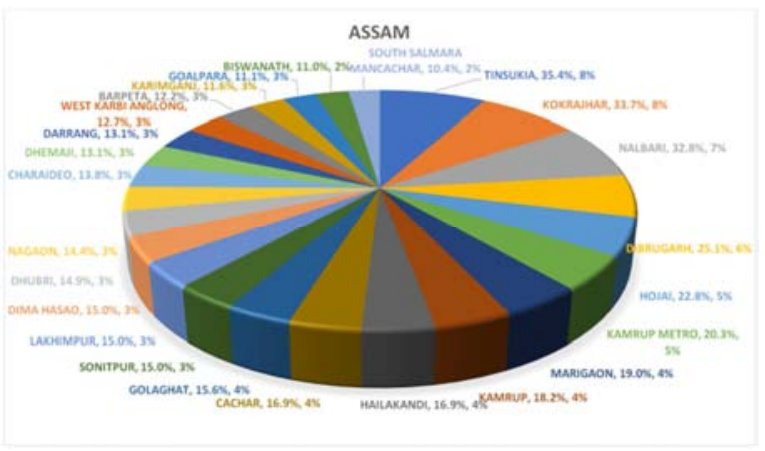

$\mathrm{C}$

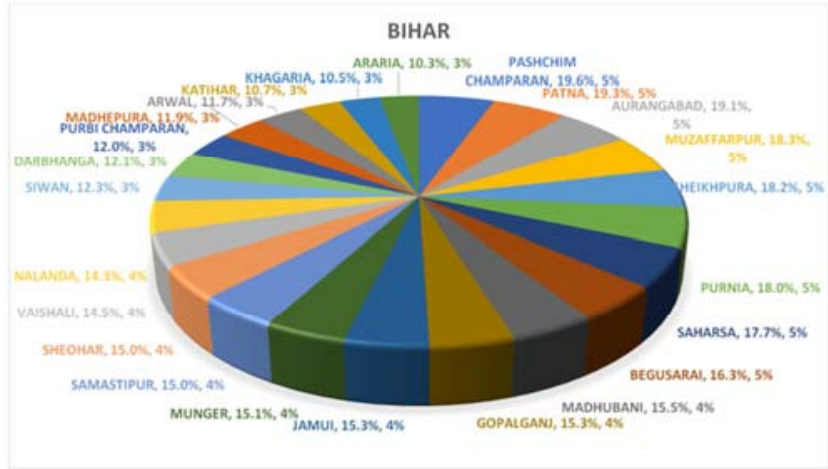

$\mathrm{D}$

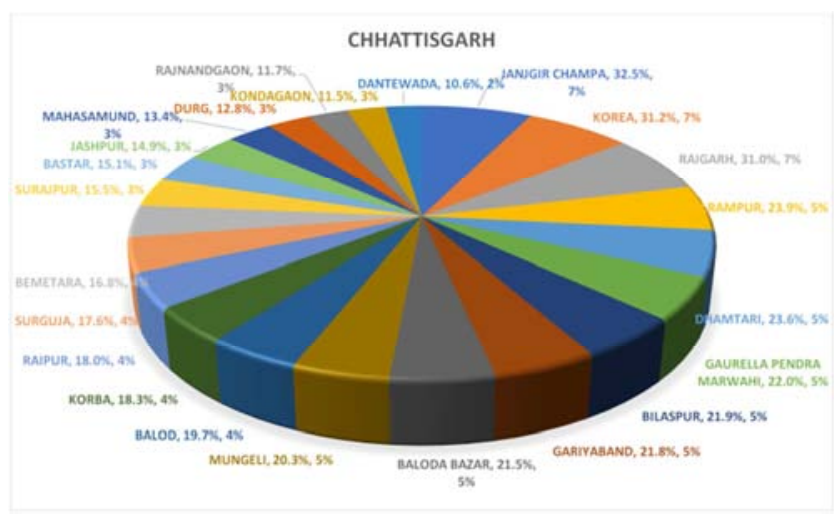

E
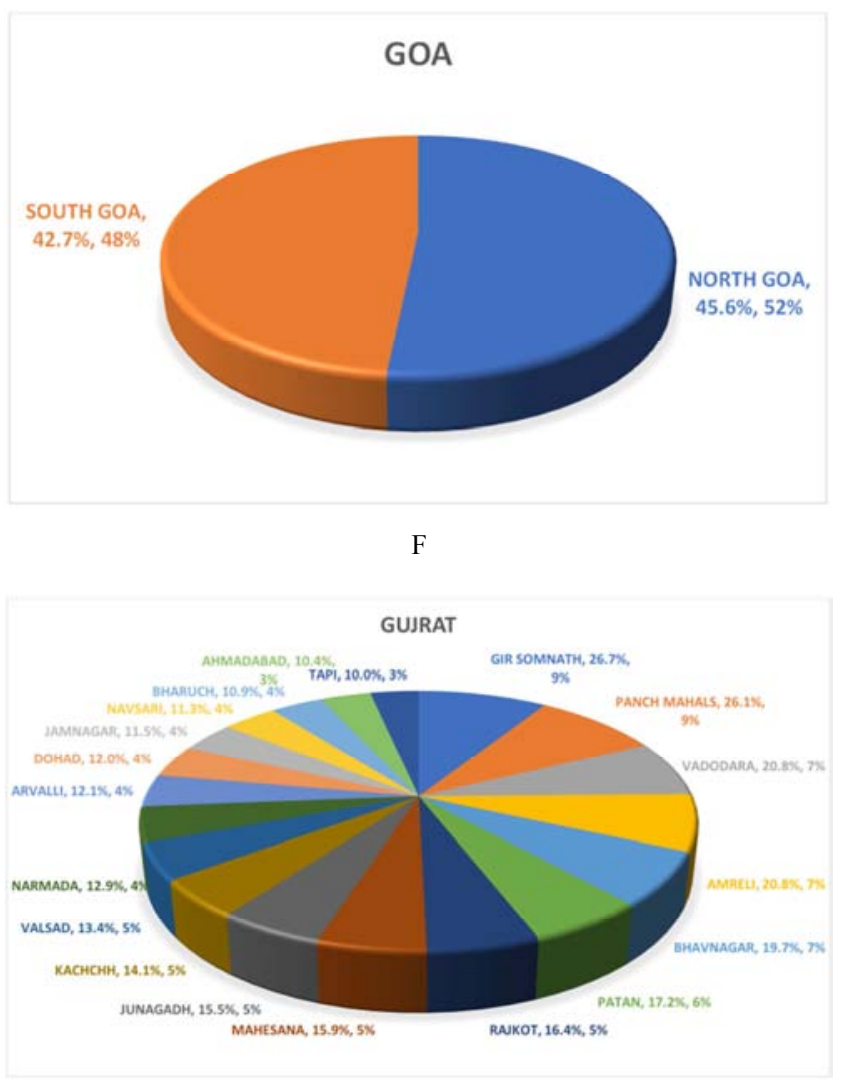

G

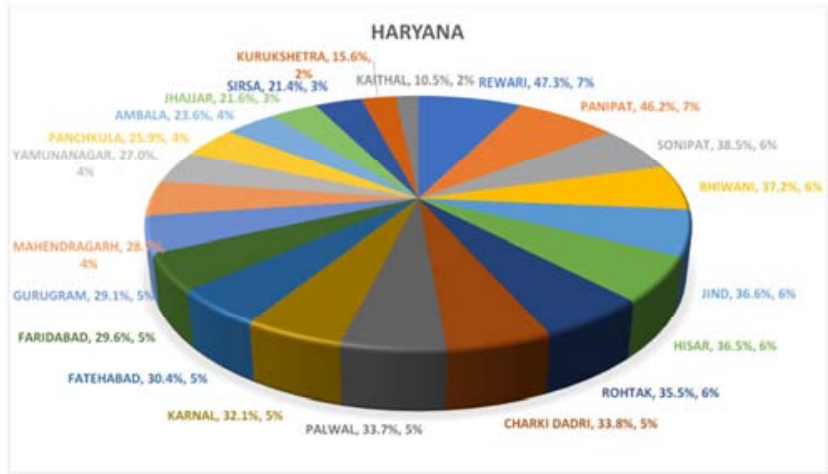

$\mathrm{H}$

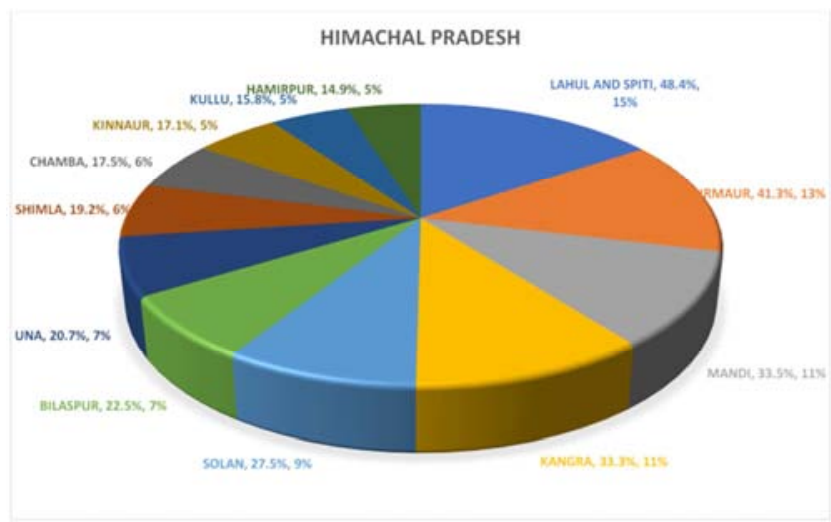

I 

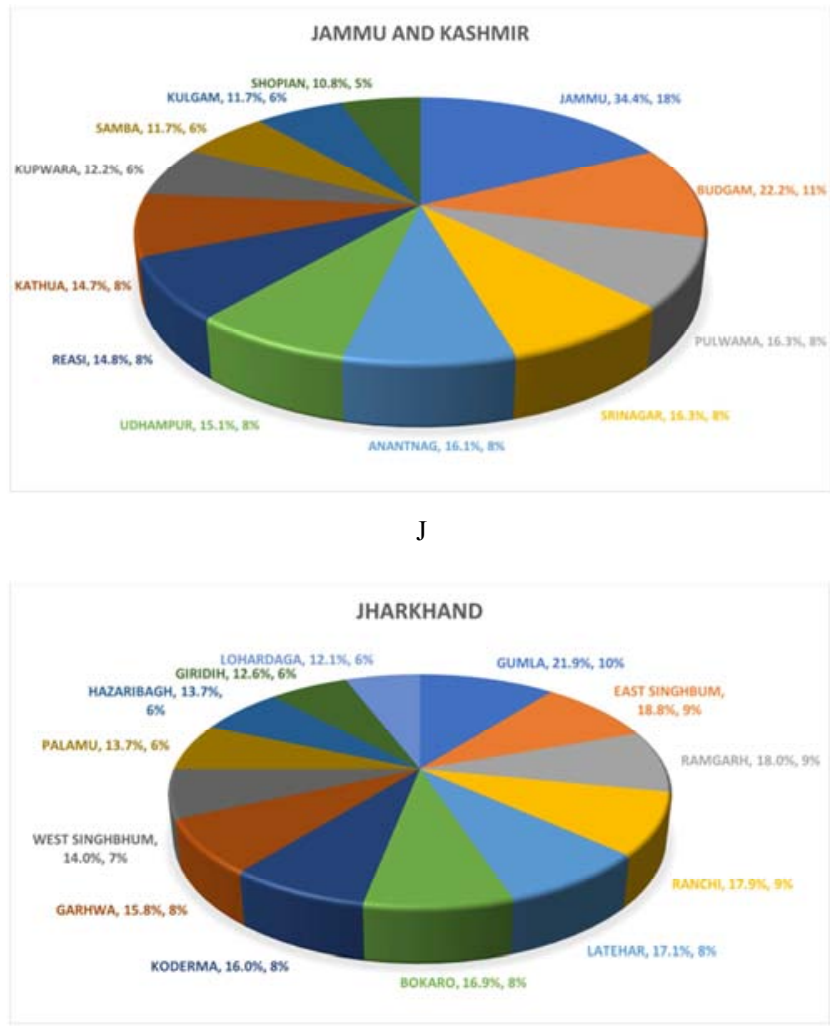

K

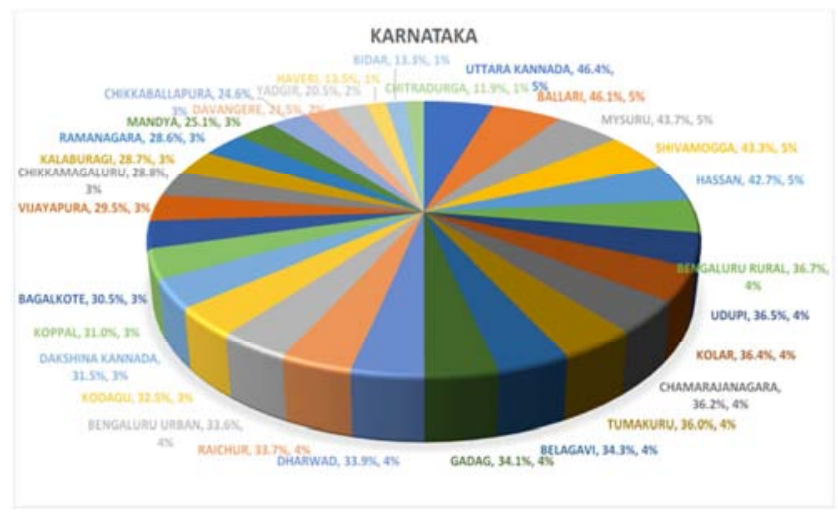

$\mathrm{L}$

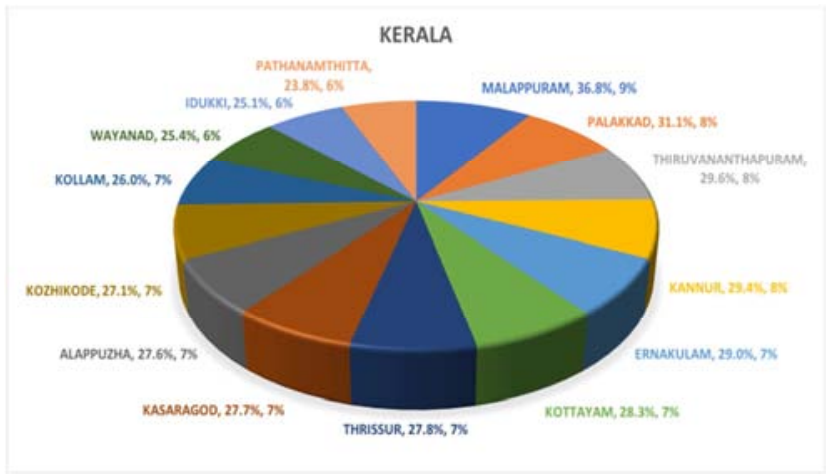

M

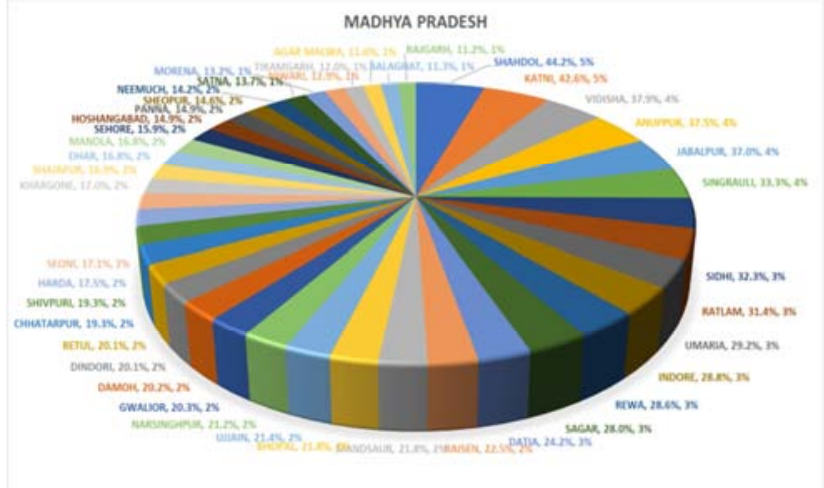

$\mathrm{N}$

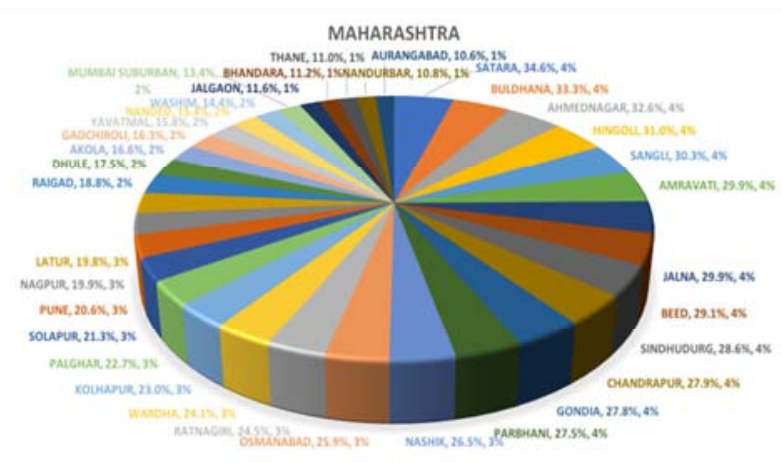

$\mathrm{O}$

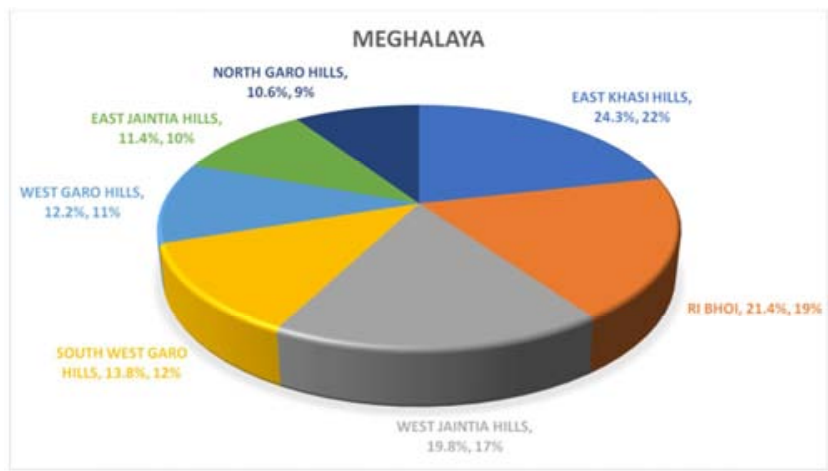

$\mathrm{P}$

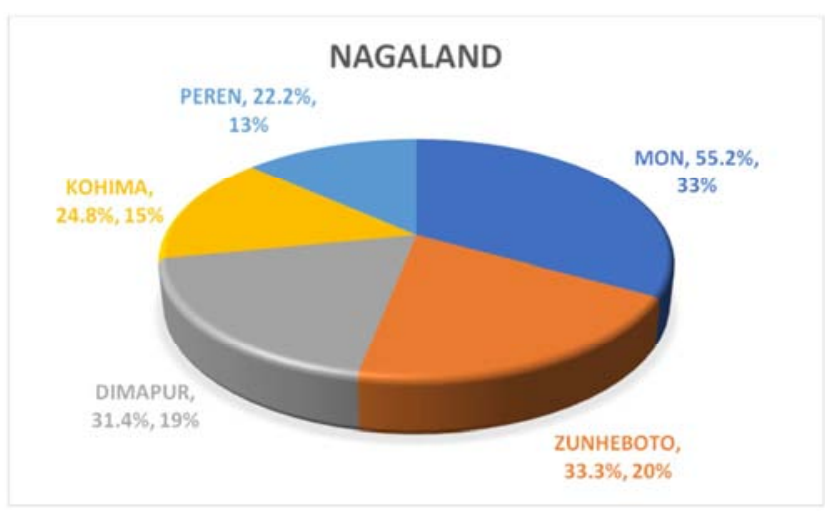

Q 


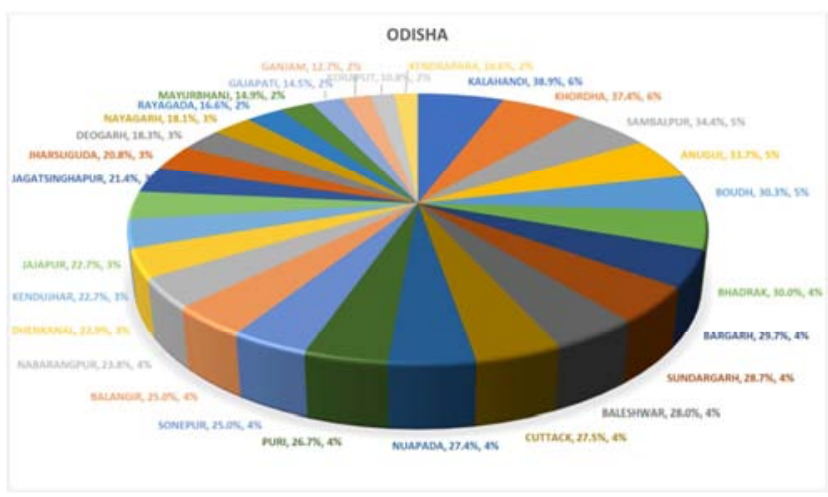

$\mathrm{R}$

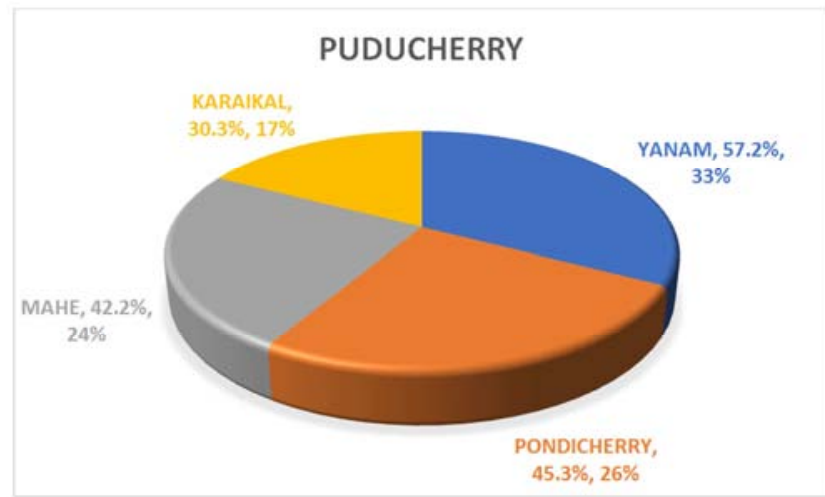

$\mathrm{S}$

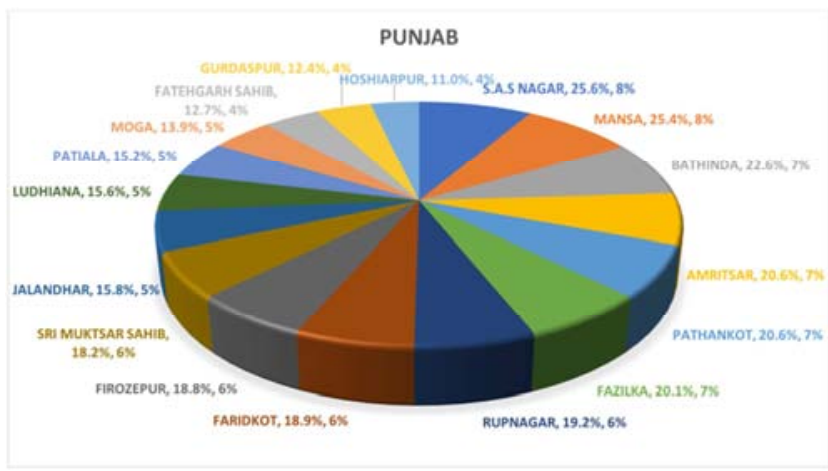

$\mathrm{T}$

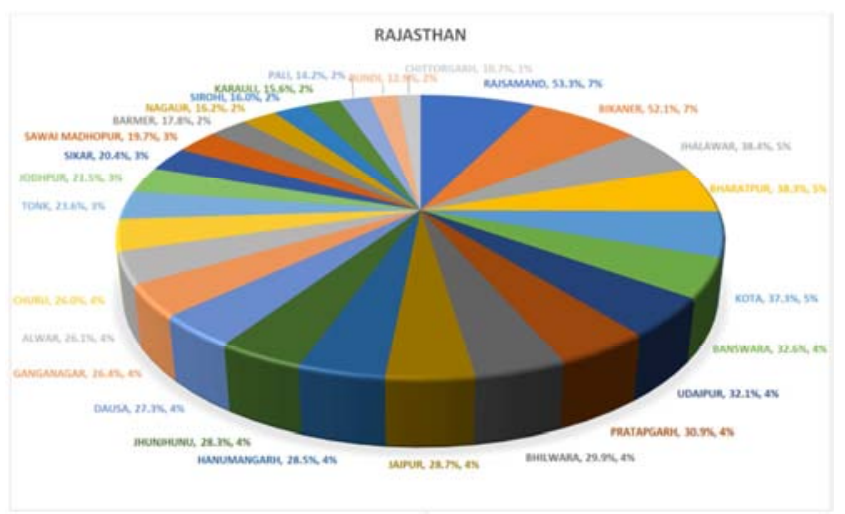

$\mathrm{U}$

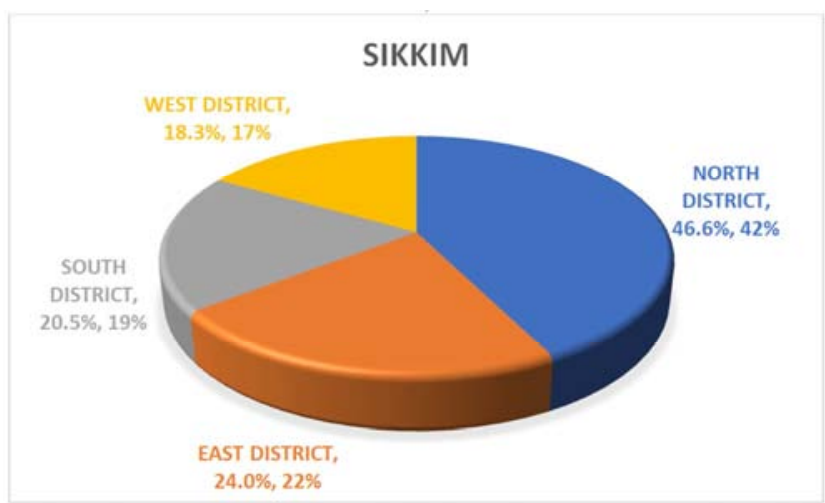

V

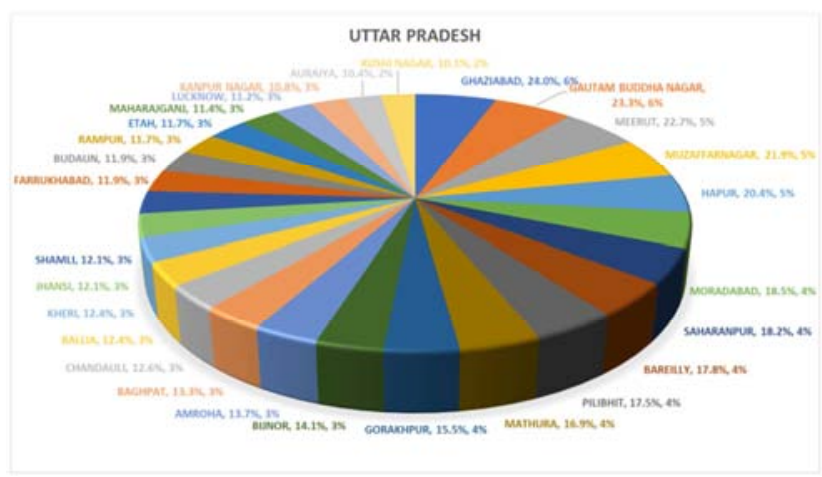

W

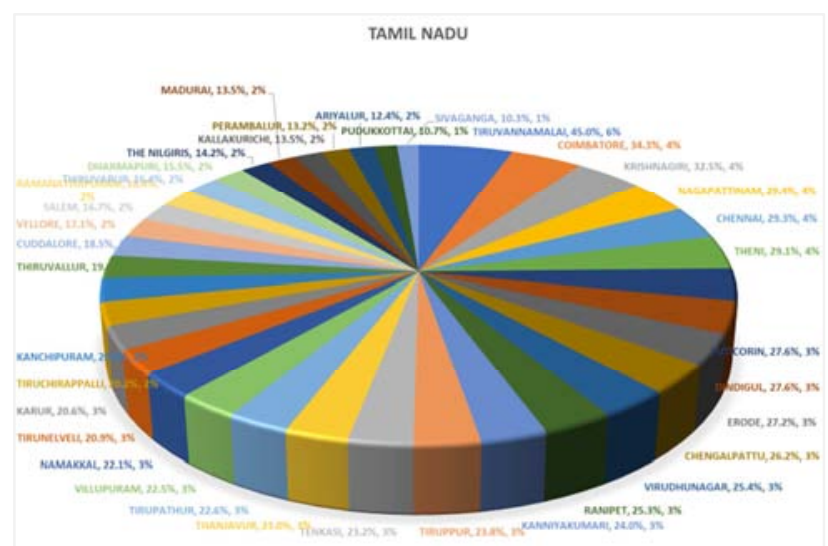

$\mathrm{X}$

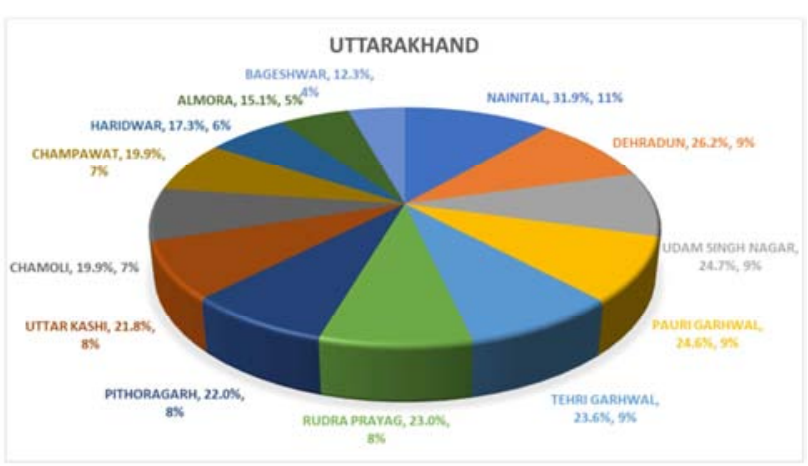

Y 


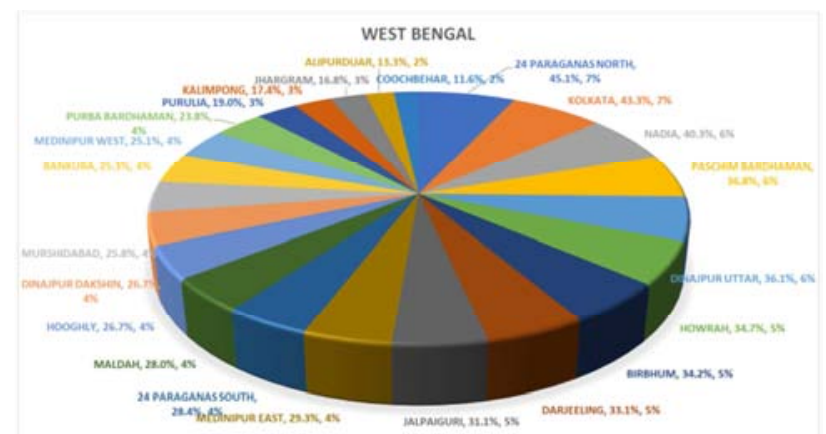

Z

A to $\mathrm{Z}$ state wise and district wise data of COVID-19

Figure 1. State wise and District wise data of COVID-19.

\subsection{The COVID-19 Cases Expanded}

Researchers are attempting to comprehend a few COVID variations currently coursing in India, where a fierce second influx of Coronavirus has crushed the country and gotten specialists unprepared. The nation recorded almost 400,000 new diseases on 9 May, taking its all out to in excess of 22 million. proof is developing that one variation first identified in quite a while may be more contagious and marginally greater at sidestepping resistance than existing variations. Creature models likewise hint that it very well may have the option to cause more serious sickness. Analysts need to know whether this variation and others may be driving the subsequent wave and what sort of peril they present internationally. In only a couple weeks, the B.1.617 variation has become the predominant strain across India and has spread to around 40 countries, including the Assembled Realm, Fiji and Singapore. [5]

\subsection{A Growing Problem}

Fourteen days prior, it looked as though various variations were behind a progression of floods in India. Genomic information demonstrated that B.1.1.7, first recognized in the Unified Realm, was prevailing in Delhi and the province of Punjab, and another variation named B.1.618 was available in West Bengal. B.1.617 was predominant in Maharashtra [5]. In any case, from that point forward, B.1.617 has surpassed B.1.618 in West Bengal, has gotten the main variation in numerous states, and is expanding quickly in Delhi. "In certain states, the flood can be attached to 617 [6].

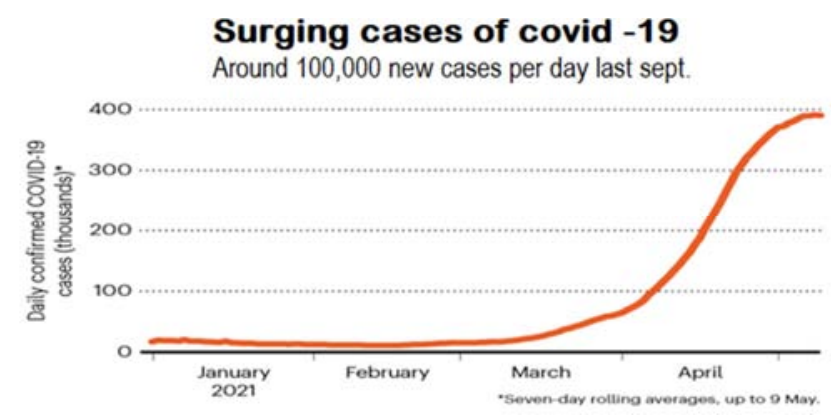

Figure 2. Surging cases of COVID-19.

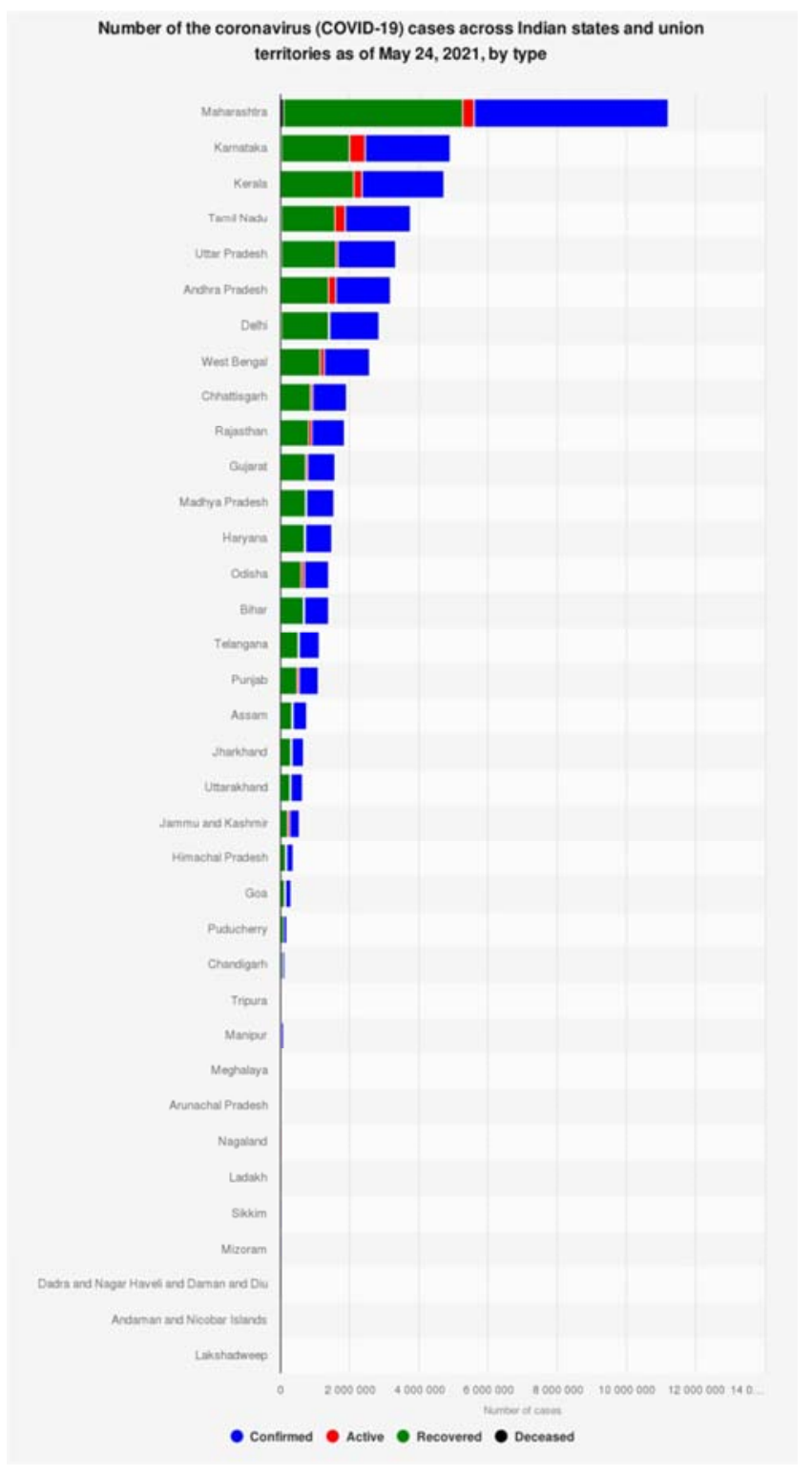

Figure 3. Corona cases in India.

Some say this could demonstrate that the variation is profoundly contagious. Its commonness has expanded over different variations in a lot of India, proposing that it has better 'wellness' over those variations, says ShahidJameel, a virologist at Ashoka College in Sonipat who seats the logical warning gathering of the Indian SARS-CoV-2 Genome Sequencing Consortia (INSACOG). The World Wellbeing Association (WHO) assigned B.1.617 a 'variation of concern'. Variations are grouped in this manner when there is proof that they spread all the more quickly, cause more extreme illness, or sidestep recently procured invulnerability better than flowing forms of the infection. On 7 May, the UK government previously pronounced the B.1.617.2 subtype a variation of worry in the Unified Realm. It uncovered that recorded B.1.617.2 contaminations in the nation had ascended from 202 to 520 in a solitary week. A few different variations of concern have had a huge effect around the world. These incorporate B.1.351, which was recognized in South Africa in late 2020; 
contemplates proposing that the College of OxfordAstraZeneca punch is less compelling against that variation prompted the country suspending its carry out. Additionally, the P.1 variation, which can avoid some insusceptibility, added to a significant second wave in Brazil early this year. Also, the profoundly contagious B.1.1.7 strain arose in the Unified Realm in late 2020 and prompted a flood of cases there and elsewhere [6].

\subsection{Emerging Mosaic}

Information on B.1.617 are just barely streaming out, yet a mosaic of discoveries implies that it has an edge over variations previously flowing in India. Indian researchers initially distinguished B.1.617 in a couple of tests in October. INSACOG inclined up observation in late January in light of a rising number of variations, and researchers saw that B.1.617 was on the ascent in Maharashtra. By mid-February, it represented $60 \%$ of cases there, says Priya Abraham, overseer of the Public Organization of Virology (NIV) in Pune. From that point forward, various sub-ancestries have arisen. In an itemized genomic and primary investigation of B.1.617 distinguished eight changes in the infection's spike protein, through which it acquires passage to cells. Two of them appear to be like transformations that have permitted different variations of worry to turn out to be more contagious, and a third looks like a change that may have permitted P.1 to halfway avoid resistance. The genomics work was sponsored up days after the fact, which shows that B.1.617 is tolerably better compared to a prior variation at entering human digestive system and lung cells in the lab. It is hazy whether this "minor" benefit could prompt more spread in reality, says lead. Little examinations in creatures recommend that the variation could cause more serious illness. In a 5 May, a group drove by virologist PragyaYadav at the NIV found that hamsters tainted with B.1.617 had more aggravation in their lungs than did creatures contaminated with different variations. [7].

\subsection{Disease-causing Potential}

This examination shows that B.1.617 can possibly cause infection. However, he alerts that "it's hard to extrapolate from hamsters to people", and says that information on infection seriousness in individuals are required that antibodies are somewhat less powerful against the variation than against others. The group gathered blood serum from nine individuals who had gotten one portion of the Pfizer immunization and tried it against an innocuous transporter infection altered to contain the SARS-CoV-2 spike protein, with the changes from B.1.617. Serum from inoculated people normally contains antibodies that can obstruct, or 'kill', the infection and keep cells from getting tainted. Killing antibodies created by the inoculated people were about $80 \%$ less strong against a portion of the changes in B.1.617, albeit this would not deliver immunization inadequate tracked down that some medical services laborers in Delhi who had been inoculated with Covishield, an Indian form of the Oxford straZeneca antibody, had become reinfected, with most cases attached to B.1.617. Also, the serum from 15 individuals who had recently been contaminated with SARS-CoV-2, and found that their antibodies killed B.1.617 about half less viably than beforehand circling strains. At the point when they tried serum from members who'd had two shots of the Pfizer immunization, they tracked down that the antibodies were about $67 \%$ less strong against B.1.617 [8]. Two other little investigations, [9] testing the Covaxin immunization made by Indian firm Bharat Biotech in Hyderabad, and an at this point unpublished examination on Covishield, showed that the antibodies keep on working. Yet, [9] noticed little drops in the viability of killing antibodies created by the Covaxin immunization. The B.1.617 variation appears to enjoy an upper hand over already coursing forms of the infection, particularly in people whose invulnerability is fading sometime after past disease or immunization [9].

\subsection{Caveats and Caution}

However, [9] alerts that these lab concentrates all include little gatherings and show more modest drops in immunizer viability, contrasted and what has been seen with different variations of concern. Researchers likewise caution that tests in serum are not generally a decent manual for whether a variation can sidestep insusceptibility from an immunization in reality. Immunizations can cause the creation of immense amounts of antibodies, so a plunge in strength probably won't be critical. Besides, different pieces of the safe framework, like Lymphocytes, may not be influenced. For instance, the B.1.351 variation has been connected to a lot more extreme drops in the strength of killing antibodies, however concentrates in people propose that numerous immunizations remain exceptionally compelling against that variation, especially at forestalling serious infection. Hence, the antibodies are probably going to stay compelling against B.1.617 and to restrict serious sickness. "The immunization is as yet working," [9]. "On the off chance that you get immunized, you "will be secured, and the seriousness will be less". By the by, "the flood in cases in India and scenes saw there is of grave concern globally", a microbial genomicist and bioinformatician at the College of Birmingham, UK, told the Science Media Center in London after the Unified Realm proclaimed B.1.617.2 a variation of concern. "This variation will currently be one to observe cautiously." Refreshing its science brief on Coronavirus, the US CDC has recognized that SARS-CoV-2, the COVID that has caused the Coronavirus pandemic, is airborne. A report in the Lancet diary in April of this current year had likewise demonstrated that SARS-CoV-2 is an airborne microorganism [10]. A Coronavirus variation that could stay airborne for almost an hour has been recognized in Sri Lanka [11]. A Lancet report in April excused transcendent logical view that SARS-CoV-2 is anything but an airborne microbe. The locations of enduring in India are difficult to appreciate. As of May 4, more than 20.2 million instances of Coronavirus had been accounted for, with a moving normal of 378000 cases a day, along with more than 222000 passing's, which 
specialists accept are probably going to be generous thinks little of. Clinics are overpowered, and wellbeing laborers are depleted and getting contaminated. Online media is loaded with urgent individuals (specialists and people in general) looking for clinical oxygen, medical clinic beds, and different necessities. However, before the second influx of instances of Coronavirus started to mount toward the beginning of Spring, [4]"endgame" of the plague. The impression from the public authority was that India had beaten Coronavirus following a while of low case checks, notwithstanding rehashed alerts of the risks of a subsequent wave and the rise of new strains [12]. Demonstrating proposed erroneously that India had arrived at crowd invulnerability, empowering carelessness and deficient arrangement, yet a serosurvey by the Indian Chamber of Clinical Exploration in January recommended that just 21\% of the populace had antibodies against SARS-CoV-2. On occasion, more aim on than attempting to control the pandemic. Regardless of alerts about the dangers of very spreader occasions, the public authority permitted strict celebrations to go on, drawing a large number of individuals from around the country, alongside enormous political conventions obvious for their absence of Coronavirus alleviation measures. The message that Coronavirus was basically over likewise eased back the beginning of India's Coronavirus inoculation crusade, which has immunized under $2 \%$ of the populace. At the government level, India's inoculation plan before long self-destructed. The public authority unexpectedly changed direction without talking about the adjustment of strategy with states, extending inoculation to everybody more seasoned than 18 years, depleting supplies, and making mass disarray and a business opportunity for immunization dosages in which states and clinic frameworks contended. The emergency has not been similarly circulated, with states, for example, Uttar Pradesh and Maharashtra caught off guard for the abrupt spike in cases, rapidly running out of clinical oxygen, medical clinic space, and overpowering the limit of incineration destinations, and with some state governments compromising those requesting oxygen or an emergency clinic bed with public safety laws [13]. Others, like Kerala and Odisha, were more ready, and have had the option to deliver sufficient clinical oxygen in this subsequent wave to send out it to different states. India should now seek after a two-dimensional technique. In the first place, the bungled immunization crusade should be supported and carried out with all due speed [14]. There are two prompt bottlenecks to survive: expanding immunization supply (some of which should come from abroad) and setting up an appropriation crusade that can cover metropolitan as well as country and less fortunate residents, who establish over $65 \%$ of the populace (more than 800 million individuals) yet face a frantic shortage of general wellbeing and essential consideration offices. The public authority should work with neighborhood and essential medical care places that know their networks and make an evenhanded circulation framework for the immunization.
Second, India should decrease SARS-CoV-2 transmission however much as could reasonably be expected while the antibody is carried out. As cases keep on mounting, the public authority should distribute exact information in an opportune way, and bluntly disclose to the public what's going on and what is expected to twist the pestilence bend, including the chance of another government lockdown. Genome sequencing should be extended to all the more likely track, comprehend, and control arising and more contagious SARS-CoV-2 variations. Neighborhood governments have started taking sickness control measures; however, the government has a fundamental job in disclosing to the public the need of veiling, social separating, ending mass get-togethers, intentional isolate, and testing. Modi's activities in endeavoring to smother analysis and open conversation during the emergency are unpardonable. Appraisals that India will see a stunning 1 million passing's from Coronavirus by Aug 1, 2021 [15]. On the off chance that that result was to occur, would be liable for directing a self-caused public calamity. India wasted its initial triumphs in controlling Coronavirus. Until April, the public authority's Coronavirus taskforce had not met in months. The results of that choice are clear before us, and India should now rebuild its reaction while the emergency seethes. The accomplishment of that exertion will rely upon the public authority taking ownership of its errors, giving capable administration and straightforwardness, and executing a general wellbeing reaction that has science at its heart.

\subsection{Indian Vaccinations Can Envision the Coronavirus and Its Effects}

The Covishield immunization depends on nucleic corrosive-based innovation and works against a solitary SARS-CoV-2 antigen, the spike protein. Covaxin depends on the inactivated antibody stage - where the spike protein as well as different antigens is introduced to the resistant framework to get a safe reaction. The odds of a deficient reaction because of unique antigenic are higher with the spike-just immunizations. Notwithstanding, there are some different systems, similar to immune response subordinate upgrade (ADE), through which even inactivated antibodies like Covaxin can improve the seriousness of sickness. During the advancement of Coronavirus immunizations, specialists raised worries over the spike-just methodology for mid-to-long haul control of the pandemic. In one article in May 2020 [15]. Issues of wide immunogenicity exist. Given that this is an RNA infection, I trust it is important that more than one viral antigen be remembered for the immunization. While the importance stays obscure to date, analysts have effectively distinguished in any event one change in the [receptor restricting domain] of the spike quality. Further changes could possibly prompt issues of unique antigenic sin with resultant illness upgrade after openness or to immunizations that essentially are not powerful later on. 'S just' antibodies hazard these issues, though immunizations that incorporate other significant SARS-CoV-2 viral antigens impressively diminish this danger. A partner and I brought comparative worry up in a definite survey of the turn of events 
and dangers related with the immunizations, distributed a year ago.

Table 2. Cumulative Coverage Report of COVID-19 Vaccination.

\begin{tabular}{|c|c|c|c|c|}
\hline \multirow{4}{*}{ India } & & \multicolumn{3}{|l|}{ Beneficiaries vaccinated } \\
\hline & & $1^{\text {st }}$ Dose & $2^{\text {nd }}$ Dose & Total Doses \\
\hline & & $13,93,75,695$ & $4,10,81,884$ & $18,04,57,579$ \\
\hline & & $(6,29,445$ in last 24 Hours $)$ & $(4,74,180$ in last 24 Hours $)$ & (11, 03, 625 in last 24 Hours) \\
\hline \multirow{2}{*}{ S. No. } & \multirow{2}{*}{ State/UT } & \multicolumn{3}{|l|}{ Beneficiaries vaccinated } \\
\hline & & $1^{\text {st }}$ Dose & $2^{\text {nd }}$ Dose & Total Doses \\
\hline 1 & A\&NIslands & 98,837 & 14,618 & $1,13,455$ \\
\hline 2 & AndhraPradesh & $53,33,983$ & $20,94,993$ & $74,28,976$ \\
\hline 3 & ArunachalPradesh & $2,15,661$ & 77,566 & $2,93,227$ \\
\hline 4 & Assam & $25,56,805$ & $7,26,365$ & $32,83,170$ \\
\hline 5 & Bihar & $68,88,249$ & $16,61,464$ & $85,49,713$ \\
\hline 6 & Chandigarh & $2,01,426$ & 72,118 & $2,73,544$ \\
\hline 7 & Chhattisgarh & $49,73,490$ & $10,48,742$ & $60,22,232$ \\
\hline 8 & Dadra\&NagarHaveli & 42,523 & 11,705 & 54,228 \\
\hline 9 & Daman\&Diu & 45,095 & 13,052 & 58,147 \\
\hline 10 & Delhi & $33,64,123$ & $10,08,618$ & $43,72,741$ \\
\hline 11 & Goa & $3,31,220$ & 92,524 & $4,23,744$ \\
\hline 12 & Gujarat & $1,09,78,124$ & $38,21,613$ & $1,47,99,737$ \\
\hline 13 & Haryana & $38,65,314$ & $8,95,230$ & $47,60,544$ \\
\hline 14 & HimachalPradesh & $17,29,593$ & $4,24,042$ & $21,53,635$ \\
\hline 15 & Jammu\&Kashmir & $22,64,605$ & $5,26,627$ & $27,91,232$ \\
\hline 16 & Jharkhand & $27,90,722$ & $6,52,498$ & $34,43,220$ \\
\hline 17 & Karnataka & $86,59,073$ & $24,06,768$ & $1,10,65,841$ \\
\hline 18 & Kerala & $62,57,447$ & $19,68,691$ & $82,26,138$ \\
\hline 19 & Ladakh & 85,330 & 37,110 & $1,22,440$ \\
\hline 20 & Lakshadweep & 20,555 & 6,485 & 27,040 \\
\hline 21 & MadhyaPradesh & $73,33,762$ & $16,31,210$ & $89,64,972$ \\
\hline 22 & Maharashtra & $1,53,44,900$ & $41,24,773$ & $1,94,69,673$ \\
\hline 23 & Manipur & $2,99,447$ & 69,560 & $3,69,007$ \\
\hline 24 & Meghalaya & $3,19,553$ & 73,859 & $3,93,412$ \\
\hline 25 & Mizoram & $2,37,504$ & 50,839 & $2,88,343$ \\
\hline 26 & Nagaland & $1,80,740$ & 51,642 & $2,32,382$ \\
\hline 27 & Odisha & $51,48,647$ & $13,94,107$ & $65,42,754$ \\
\hline 28 & Puducherry & $1,79,241$ & 49,101 & $2,28,342$ \\
\hline 29 & Punjab & $34,27,100$ & $6,97,985$ & $41,25,085$ \\
\hline 30 & Rajasthan & $1,18,95,029$ & $29,57,371$ & $1,48,52,400$ \\
\hline 31 & Sikkim & $1,64,814$ & 59,573 & $2,24,387$ \\
\hline 32 & TamilNadu & $50,05,098$ & $18,68,492$ & $68,73,590$ \\
\hline 33 & Telangana & $43,85,309$ & $10,62,232$ & $54,47,541$ \\
\hline 34 & Tripura & $9,40,372$ & $5,03,059$ & $14,43,431$ \\
\hline 35 & UttarPradesh & $1,13,91,619$ & $31,77,256$ & $1,45,68,875$ \\
\hline 36 & Uttarakhand & $18,96,860$ & $6,75,687$ & $25,72,547$ \\
\hline 37 & WestBengal & $88,24,252$ & $36,76,768$ & $1,25,01,020$ \\
\hline 38 & Miscellaneous & $16,99,273$ & $13,97,541$ & $30,96,814$ \\
\hline
\end{tabular}

Source: https://www.mohfw.gov.in

\section{Conclusion}

A few signals as of now highlight this uncommon relationship at work. As talked about above, numerous clinicians and a presumed collection of autonomous specialists have raised the chance of higher contamination rates among immunized people. We ought not excuse this wonder as being connected uniquely to hazardous or unseemly practices, regardless of whether the two components lead to reciprocal results. All things being equal, we should bend over backward to research whether our antibodies have this impact, zeroing in a portion of our endeavors on creating multi-strain immunizations, and guarantee adherence to Coronavirus fitting practices. Analysts ought to survey the recurrence and seriousness of sickness among immunized and unvaccinated companions. We ought to likewise isolate the discoveries dependent on singular immunization use. Right now, India is in the grasp of an exceptional flood in Coronavirus cases. The things we are doing to secure ourselves should not be permitted to incidentally fuel the illness.

\section{References}

[1] https://www.latimes.com/california/story/2021-04-06/doublemutant-coronavirus variant-found-California.

[2] Yadav PD, Nyayanit DA, Sahay RR, et al. Isolation and characterization of the new SARS-CoV-2 variant in travellers from the United Kingdom to India: VUI-202012/01 of the B.1.1.7 lineage. J Travel Med 2021; 28. 
[3] https://www.thehindu.com/news/national/pfizer-withdraws-e mergency-use-authorisation-application-for-its-COVID-19-va ccine-in-india/article33757258.ece.

[4] https://indianlekhak.com/india-news/in-the-endgame-of-the-ep idemic-in-india-the-health-minister-says.

[5] Sarah Cherian, Varsha Potdar, Santosh Jadhav, Pragya Yadav, Nivedita Gupta, Mousmi Das, Partha Rakshit, Sujeet Singh, Priya Abraham, Samiran Panda, NIC team. Convergent evolution of SARS-CoV-2 spike mutations, L452R, E484Q and P681R, in the second wave of COVID-19 in Maharashtra, India. Bio Rxiv 2021.04.22.440932.

[6] Markus Hoffmann, Heike Hofmannwinkler, Nadine Krüger, Amy Kempf, Inga Neh meier, Luise Graichen, Anzhalika Sidarovich, Anna-Sophie Moldenhauer, Martin S. Winkler, Sebastian Schulz, Hans-Martin Jäck, Metodi V. Stankov, Georg M. N. Behrens, Stefan Pöhlmann. SARS-CoV-2 variant B.1.617 is resistant to Bamlanivimab and evades antibodies induced by infection and vaccination. Bio Rxiv 2021.05.04.442663.

[7] Pragya D. Yadav, Sreelekshmy Mohandas, Anita M Shete, Dimpal Nyayanit, Nivedita Gupta, Deepak Y. Patil, GajanaN. Sapkal, Varsha Potdar, Manoj Kadam, Abhimanyu Kumar, Sanjay Kumar, Deepak Suryavanshi, Chandrashekhar S. Mote, Priya Abraham, Samiran Panda, Balram Bhargava. SARS $\mathrm{CoV}-2$ variant B.1.617.1 is highly pathogenic in hamsters than B.1 variant. Bio Rxiv 2021.05.05.442760.
[8] Isabella Ferreira, Rawlings Datir, Guido Papa, Steven Kemp, Bo Meng, Partha Raksh, Sujeet Singh, Rajesh Pandey, Kalaiarasan Ponnusamy, V. S. Radhakrishnan. The Indian SARS-CoV-2 Genomics Consortium (INSACOG), The COVID-19 Genomics UK (COG-UK) consortium, Kei Sato, Leo James, Anurag Aggarwal, Ravindra K. Gupta. SARS-CoV-2 B.1.617 emergence and sensitivity to vaccine-elicited antibodies. Bio Rxiv 2021.05.08.443253.

[9] Yadav, P. D. et al. Clin. Infect. Dis. https://doi.org/10.1093/cid/ciab411 (2021).

[10] www.thelancet.com Vol 397 May 8, 2021

[11] www.thelancet.com Vol 397 May 1, 2021.

[12] https://www.thelancet.com/journals/lancet/article/PIIS0140-67 36(21)00993-4/fulltext.

[13] https://www.aljazeera.com/news/2021/4/27/indian-state-crack s-down-on-hospitals-flagging-oxygen-shortage.

[14] https://www.bloomberg.com/news/articles/2021-04-29/how-in dia-s-vaccine-drive-crumbled-and-left-a-country-in-chaos.

[15] https://www.ncbi.nlm.nih.gov/pmc/articles/PMC7252125/pdf/ main.pdf. 